\title{
An Exploratory Study on the Relationship between Creativity and Processing Speed for Gifted Children
}

\author{
Abdulkadir Bahar ${ }^{1} \&$ Mehmet Ali Ozturk ${ }^{2}$ \\ ${ }^{1}$ School of Education, University of Wisconsin-Stevens Point, Wisconsin, United States of America \\ ${ }^{2}$ Department of Special Education, Biruni University, Istanbul, Turkey \\ Correspondence: Abdulkadir Bahar, School of Education, College of Professional Studies, 1901 Fourth Avenue, \\ UW-Stevens Point, Stevens Point, WI 54481-3897, United States of America. E-mail: kbahar@uwsp.edu
}

Received: October 24, 2017

Accepted: December 7, 2017

Online Published: February 25, 2018

doi: $10.5539 /$ ies.v $11 \mathrm{n} 3 \mathrm{p} 77$

URL: https://doi.org/10.5539/ies.v11n3p77

\begin{abstract}
This study explored the relationship between processing speed and five dimensions of creativity, which were fluency, originality, elaboration, abstractness of titles, and resistance to premature closure (RPC). It is the first empirical study that examines this relationship, also relating it to gender and level of giftedness. Data came from 133 gifted students at grades one through four in three private schools in Istanbul, Turkey. Creativity was measured through the Torrance Test of Creative Thinking - Figural. Scores from the Coding subtest of the Wechsler Intelligence Scale for Children were used as the data on processing speed. The findings showed that girls had significantly higher scores in processing speed, elaboration, abstractness of titles, and RPC. There were no significant differences in fluency and originality. While fluency and originality were the only two subscores correlated with processing speed for boys (both positively correlated), four subscores were correlated with processing speed for girls (all four negatively correlated). Girls had higher processing speed scores in the group of low giftedness, but not in the group of high giftedness. A distinct finding about the boys of high giftedness was the high positive interrelationships among originality, fluency, and processing speed, which were not there for boys of low giftedness or girls of high giftedness. With its findings, the study supports some of the previous explanations around the topic, and generates new hypotheses to be tested experimentally.
\end{abstract}

Keywords: processing speed, creativity, gifted, Wechsler intelligence scale for children, Torrance test of creative thinking

\section{Introduction}

The relationship between creativity and mental processing speed has been of interest to researchers even though most of the studies on the topic are relatively recent and inconclusive. Some frontrunner researchers of the field of gifted education have identified processing speed and creativity as important parts in their conceptualizations of giftedness (e.g., Feldman, 1982; Renzulli, 1978; Sternberg, 1985; Tannenbaum, 1992). In Renzulli's three ring conception of giftedness, gifted behavior is defined in a way that reflects an interaction among three basic clusters of human traits - high levels of task commitment, high levels of creativity, and above average ability (Renzulli \& Reis, 1997). Although processing speed is not considered as one of the clusters in Renzulli's theory, Renzulli's open-ended description of above average ability allows seeing quick and efficient response to tasks as an indication of above average ability. Similar to Renzulli's conception of giftedness, Sternberg's triarchic theory defines giftedness as interplay of analytical, practical, and creative aspects of the mind (Sternberg, 1985). In addition, Sternberg asserts that gifted individuals complete tasks and solve problems with speed and efficiency by automatizing certain cognitive processes (as cited in Paz-Baruch, Leikin, Aharon-Peretz, \& Leikin, 2014). Yet, Sternberg does not make any explicit statements about the relationship between creativity and processing speed in gifted learners. It is actually the aim of the present study to examine this relationship for gifted children.

This relationship also bears importance for the topic of giftedness, since processing speed might be the meeting ground for the functions of creativity and giftedness. In this sense, processing speed might play a key role in the identification of similarities and differences between creativity and intelligence. With some common neurological attributes, creativity and high level of intelligence may enjoy the same high processing speed. On the other hand, processing speed might differ based on types of tasks involved and types of cognitive processing skills required. Consequently, processing speed might be an indicator of this differentiation between the functions of creativity and 
those of giftedness. Through identifying the realms of creativity and giftedness in this way, such line of research might help resolve a long-lasting controversy on the definitions of creativity and intelligence.

\subsection{Processing Speed}

Processing speed is usually defined as a robust psychometric factor that is measured at which individuals perceive and process incoming information (Carroll, 1993). However, depending on the operational definition of the construct of processing speed, the tools and tasks we use to measure processing speed might vary. For example, Shanahan et al. (2006) defined processing speed operationally as reflecting cognitive efficiency involved in higher level cognitive information, integrating lower level perceptual stimuli, and output speed. Therefore, we do not have enough evidence to claim whether all speeded tasks are measuring the same underlying cognitive process (Shanahan et al., 2006). Processing speed has been measured traditionally through simple and complex response time measures that require speed of visual search, eye-hand coordination, motor speed, visual short-term memory, and capacity for sustained effort and concentration (Wechsler, 1997; Woodcock, McGrew, \& Mather, 2001). In the present study, the operational definition of processing speed is the speed of a cognitive mechanism that provides understanding and acting upon stimuli through complex tasks including "copying nonsense symbols using a digit-symbol code key" and "matching these symbols appearing in two groups rapidly" (Wechsler, 1974, p. 32).

\subsection{Creativity}

Creativity has been one of the controversial constructs that was diversely defined in the literature. However, contemporary researchers seem to have reached a general agreement that creativity involves the production of novel, useful products (Mumford, 2003). In one of the earliest definitions, Torrance (1966) defined creativity as a "process of becoming sensitive to problems, deficiencies, gaps in knowledge, missing elements, disharmonies, and soon; identifying the difficulty; searching for solutions, making guesses, or formulating hypotheses about the deficiencies: testing and retesting these hypotheses and possibly modifying and retesting them; and finally communicating the results" (p. 6).

In his theoretical model of human intelligence, which is named as the Structure of the Intellect, Guilford (1967) separated convergent (single solutions, closed-ended tasks) and divergent (multiple solutions, open-ended tasks) thinking abilities as two distinct constructs. Although he highlighted that creativity could not be attributed solely to divergent thinking, he linked both, and asserted that divergent thinking, or the ability to generate diverse and numerous ideas is one major condition of creativity (Guilford, 1950). Similarly, several other researchers accepted divergent thinking as a criterion or predictor of creativity (Plucker, 1999; Runco, 1986, 2008; Silvia et al., 2008; Vincent, Decker, \& Mumford, 2002). Guilford (1967) highlighted several abilities that are related to divergent thinking and also contribute to creativity. Some of these abilities, such as fluency (ability to generate many ideas), flexibility (ability to produce ideas that show a variety of possibilities or realms of thought), originality (ability to produce uncommon or unique ideas), and elaboration (ability to add a variety of details to a piece of information) were found to be common properties of creative individuals (Guilford, 1967).

Creative thinking performances have been widely assessed by means of tests that measure divergent thinking ability (Runco \& Jaeger, 2012, Silvia et al., 2008). The first tests of divergent thinking were developed by Guilford $(1950,1967)$ about six decades ago during his studies on intelligence (Fleith, Bruno-Faria, \& Alencar, 2014). The Torrance Tests of Creative Thinking (Torrance, 1966, 1974) have been the most widely employed battery that has been used as an assessment of creative thinking and also as a criterion in the identification of gifted students for educational programs (Cramond, 1999). This battery includes verbal and figural parts, both with two distinct forms. The battery aimed, in its original version, at assessing four dimensions of creativity, which were fluency, flexibility, originality, and elaboration. However, in the latest version, flexibility was excluded, while other dimensions were included, such as abstractness of titles and resistance to premature closure.

In this study, The Torrance Test of Creative Thinking (TTCT), Figural assessment was used to measure five dimensions of creativity. In the 2008 norms and technical manual of TTCT (Torrance, 2008), these five dimensions are defined operationally. Fluency is measured by counting the number of relevant ideas that show an ability to produce a number of figural images. Originality is defined as the ability to produce uncommon or unique responses, and measured by counting the number of statistically infrequent ideas. Elaboration is defined as the ability to develop and elaborate on ideas, and measured by counting the number of added ideas that demonstrates subject's ability to develop, embellish, or elaborate ideas (Torrance, 2008). Abstractness of titles is defined as the degree beyond labeling based on a rationale that creativity requires a person to sense what is truly essential (Torrance, 2008). It measures the abstraction of thought and degree a title moves beyond simple labeling of the pictures drawn (Kim, 2006). Resistance to premature closure is defined as the degree of psychological openness 
based on the idea that creative behavior requires one to keep an open mind when processing information (Torrance, 2008).

\subsection{The Relationship between Creativity and Processing Speed for Gifted Children}

The literature on this topic can be roughly divided into two groups. The first group is the body of research and writings that approached the topic through the framework of the relationship between creativity and intelligence, since processing speed is widely used as a subscale of intelligence tests (e.g. Wechsler Intelligence Scale for Children). The majority of the contemporary research views intelligence and creativity as distinct constructs that are only weakly related (Batey \& Furnham, 2006; Kaufman, 2009; Kim, 2005; Kim, Cramond, \& VanTassel-Baska, 2010; Preckel, Holling, \& Wiese, 2006; Runco, 2007; Sligh, Conners, \& Roskos-Ewoldsen, 2005; Sternberg \& O’Hara, 1999). For example, Kim's (2005) meta-analytic study found the mean correlation coefficient between these two traits to be small $(r=.17)$.

As a first study of its kind, Wallach and Kogan (1965) documented that the intelligence and creativity relationship was strongly dependent on the degree of speededness of tasks. Many other studies suggest that processing speed accompanies intellectual giftedness (Dark \& Benbow, 1991; Jensen, Cohn, \& Cohn, 1989; Vernon, 1983). For example, gifted children have been found to be quicker than those with average IQ in response time (Spiegel \& Bryant, 1978) and decision time (Deary, 2000; Detterman, 1987; Steiner \& Carr, 2003). However, several researchers (Davidson \& Sternberg, 1984; Shore \& Lazar, 1996) state that gifted children actually spend more time on some cognitive tasks compared to non-gifted children. More specifically, although gifted adolescents were found to be quicker in solving complex pattern recognition problems, they spent more time during exploration and planning stages of a problem (Shore \& Lazar, 1996).

Still at the intersection of creativity and intelligence, there have been claims about differential strength of the relationship between these two variables at varying degrees of intelligence. Actually, intelligence thresholds in the correlations between creativity and intelligence have been investigated since Torrance (1962) reported differences in these correlations in the intelligence continuum. Some studies (Preckel et al., 2006; Kim, 2005; Runco \& Albert, 1986) have indicated an absence of these variations across the intelligence continuum. Although findings of prior studies present evidence for each of these perspectives, creativity is shown as a lower order factor of intelligence in several influential models of intelligence (Jauk, Benedek, Dunst, \& Neubauer, 2013). For example, in Guilford's (1967) structure of intellect model, creativity appears in the form of divergent production. Furthermore, Guilford suggests that the relationship between creativity and intelligence may vary at different levels of cognitive ability. Guilford's assertion that high intellectual ability is required for high creativity has been popular as the "threshold hypothesis" (Jauk et al., 2013). According to Guilford's threshold hypothesis, "the pattern of bivariate distribution of the cases suggests that although high IQ is not a sufficient condition for high divergent production ability, it is almost a necessary condition" (p. 168).

In an empirical study, Preckel et al. (2006) investigated the relationship between intelligence and creativity with special attention given to the hypotheses of threshold theory. They examined the theory with a representative sample of 1328 German school students who were at ages 12 to 16 from different types of schools. Significant positive correlations between intelligence and creativity were found, while no evidence for a threshold relationship between divergent thinking and reasoning ability was obtained. However, when controlling for processing speed, they found that relations between intelligence and creativity were much weaker. Furthermore, Preckel et al. (2006) found that the relation between intelligence and divergent thinking decreased significantly when controlling for mental speed. It is highly likely that the relation between intelligence and creativity might be due partly to the variance both constructs share with mental speed. Highlighting the importance of processing speed, Preckel et al. (2006) recommended future researchers to clarify relationships among creativity, intelligence, mental speed, and speededness of tasks.

The second group of studies on the relationship between processing speed and creativity are the ones that investigated the topic without a major reference to intelligence. As Rindermann and Neubauer (2004) indicated, the study of the relationship between speed of information processing and cognitive abilities has a long history of research, and goes back to early studies of Galton (1883), who tried to measure reaction time in relation to independent indicators of extraordinary accomplishments. After Roth's (1964) study, which documented a higher speed of processing in brighter subjects, several empirical studies were conducted to investigate the influence of processing speed on other cognitive abilities including creativity (Deary, 2000; Neubauer, 1997).

Deary (1995) regarded processing speed as an important factor for the development of cognitive abilities including creativity. The speed of processing, during the early stages of perception, is documented to determine the development of mental abilities; since, throughout years, small individual differences in processing speed 
might accumulate to large differences in abilities such as creativity, vocabulary, and performance (Brand, 1981; Jensen, 1982). Furthermore, a high speed of processing in basic mental functions is found to make higher cognitive operations, such as creative thinking, more efficient (Deary, 1995).

Combining suggestions and findings of prior studies (Brand, 1981; Davidson \& Sternberg, 1984; Deary, 1995; Jensen, 1982; Preckel et al., 2006; Shore \& Lazar, 1996), we may conclude that creativity, giftedness, and processing speed are interrelated, and the relationships among the three might vary based on the structure of conducted tasks and types of cognitive processing skills involved in these tasks.

\subsection{Gender Differences in Processing Speed and Creativity}

Although findings vary based on the type of tasks used, women are found to be faster on tests of processing speed including the digit and symbol coding task of the Wechsler tests (Camarata \& Woodcock, 2006; Feingold, 1992; Longman, Saklofske, \& Fung, 2007; Majeres, 2007; Reynolds, Chastain, Kaufman, \& MacLean, 1987; Sheppard \& Vernon, 2008; Silverman, 2006; Wechsler, 1997). For example, Longman et al. (2007) studied gender differences on Wechsler Adult Intelligence Scale - III index scores in the American $(n=2450)$ and Canadian $(n=$ 1104) standardization samples. In the American sample, men had a slightly higher memory index score, verbal comprehension index score, and perceptual organization index score; while women had a higher processing speed index score. In the Canadian sample, the only significant difference between the groups was on the processing speed index score, with women having slightly higher scores.

The impact of gender on creative ability has been of great interest to many researchers. Findings in this line of research appear controversial and puzzling. While many empirical investigations have reported no significant differences in creative performances of females and males (Ayyıldız-Potur \& Barkul, 2009; Charyton \& Snelbecker, 2007; Kaufman, 2006; Kogan, 1974), a substantial number of studies have indicated differences in creativity scores of females and males (Anwar, Shamim-urRasool, \& Haq, 2012; Awamleh, Al Farah, \& El-Zraigat, 2012; DeMoss, Milich, \& DeMers, 1993; Hong, Peng, O’Neil, \& Wu, 2013; Kousoulas \& Mega, 2009; Stephens, Karnes, \& Whorton, 2001; He, Wong, Li, \& Xu, 2013; Stoltzfus, Nibbelink, Vredenburg, \& Thyrum, 2011).

In an effort to further understand the impact of gender on creativity, some researchers have also looked into domain and age related differences in creativity between females and males (Flaherty, 1992; Stephens et al., 2001; Tegano \& Moran, 1989). Even when clustering the findings by domain and age, the findings have still been inconclusive. For example, Stephens et al. (2001) investigated gender differences in creativity scores of 165 third and fourth grade students, using the Torrance Test of Creative Thinking (TTCT) Figural Form A. The results indicated that females performed significantly better than males in the subtests of originality and creative index, while no differences existed in other dimensions, including elaboration, fluency, abstractness of titles, and resistancy to closure. In a recent study, Bart, Hokanson, Sahin, and Abdelsamea (2015) investigated gender differences in creative thinking subtests among 8th and 11th grade students. The study participants included 996 8th and 74811 th grade students attending a suburban independent public school district in Minnesota, which is in the Midwest USA. Bart et al. found significant differences on the majority of the subtests in favor of females among both 8th and 11th grade students. However, no significant differences appeared in the fluency subtest between males and females among the 8th grade students. The results also revealed that there were no statistically significant differences in the fluency and originality subtests between males and females among the 11th grade students.

Bart et al. (2015) find creativity-related gender differences possible. However, Baer and Kauffman (2008) highlight the fact that neither biological maleness nor femaleness leads to greater creativity. Furthermore, some researchers related these differences to sociocultural factors (Abraham, 2016; Abra, 1991; Simonton, 1994). For example, Abraham (2016) asserted that several socialization factors such as, gender labeling, different perceptions and expectations for daughters compared to sons, variation in schooling, and over-socialization of girls, restrict the development of creative thinking skills. While it is likely that gender differences in creativity are, to a certain extent, the product of social factors, to date, no study has systematically compared the impact of biological factors with that of sociocultural factors on gender differences in creative performances.

\subsection{The Significance of the Present Study}

Many contemporary researchers and experts in the field of gifted education have included creative thinking abilities, along with intelligence, in their conceptualization of giftedness. Traditionally, fostering creative thinking skills such as fluent, original, and elaborative thinking has been one of the major goals of programs designed for gifted learners. At this point, understanding the interplay between creativity and processing speed might help researchers and practitioners improve their methods of identification of the gifted as well as their program development for the gifted. For example, we believe it is important to know whether low processing speed might 
be a disadvantage in identification for some students, even though they are as creative and intelligent - if not more - as their peers identified as gifted. Similarly, knowledge of the interaction between creativity and processing speed might enlighten our understanding of the cognitive development process, which, in turn, might inform our approach to school-aged children as well as those of earlier stages of cognitive development. Such a change in our approach would also lead to significant revisions in the programs designed for the gifted. In sum, the present study might shed light to the conceptualization and identification of giftedness as well as to the development of programs for the gifted.

In this study, we wanted to research the relationship between processing speed and dimensions of creativity. Although several researchers highlighted the important role of processing speed on the relationship between creativity and intelligence, much remains unknown about the specific relationship between processing speed and dimensions of creativity. To our knowledge, there is yet no empirical research on this relationship. We investigated this topic not only as a bivariate relationship but also by relating it to the variables of gender and level of giftedness. In this respect, we believe this study will fill an important gap. The following research questions guided this study:

1) Are there differences between gifted elementary girls and boys in processing speed and dimensions of creativity?

2) To what extent are the relationships between dimensions of creativity and processing speed different/similar in gifted elementary girls and boys?

3) To what extent are the relationships between dimensions of creativity and processing speed different/similar in groups of low and high giftedness for elementary aged children?

\section{Method}

\subsection{Design}

The present study is a non-experimental research with a correlational design. Consistent with its exploratory nature, it examines group mean differences and bivariate correlations for the variables under investigation. In this way, it aims to inform future studies on the topic about the measurement of the variables in question and those with stronger research designs that might allow causal inferences about these variables.

\subsection{Participants}

The data in this study were collected from an enrichment program designed for gifted students at one of the largest private school chains in Turkey. The program has been established by a program committee, which included one professor of gifted education, one researcher, one specialist, and one certified gifted education teacher. The goal of the program was to develop participating gifted students' creative thinking skills through enrichment activities created by the program committee. Students were selected through a two-step evaluation that included teacher nominations and IQ tests scores. At the first step of the selection process, subject and homeroom teachers were requested to nominate the top ten percent of their students based on a checklist prepared by the program committee. At the second step, WISC-R was administered to all nominated students, and students who scored 115 or higher at WISC-R were identified as gifted by the program committee.

Participants of the study were 133 students at grades 1 through 4 in three private schools, which were located in one of the largest metropolitan areas of Turkey. These students were identified to participate in the program designed for gifted students for the school year of 2014-2015. The age range of these 75 male and 58 female students was from 71 months to 108 months, with a mean of 85 months and a standard deviation of 9 months. The IQ scores in the entire sample ranged from 118 to 152 , with a mean of 134 and a standard deviation of 9 . The IQ scores of boys ranged from 122 to 150 , with a mean of 136 and a standard deviation of 8.4. The IQ scores of girls ranged from 118 to 152 , with a mean of 132 and a standard deviation of 9.3. Because the data in this study on processing speed, IQ scores, and subscores of creativity were all collected before the program started, and none of the participants had any history of attending other programs for the gifted, no effect of intervention on participants could have existed. Therefore, no information regarding the intervention, the teacher training program, or the gifted program evaluation has been provided here.

\subsection{Measurement Instruments}

\subsubsection{Torrance Test of Creative Thinking-Figural (TTCT-F) Form A}

The Turkish version of TTCT-F Form A was administered to measure creativity of the participants. The original test was developed for an age range of Kindergarten through adult (Torrance, 2008), and it was translated into Turkish by Doğan-Yarbrough in 2011 with the permission of Scholastic Testing Service, Inc., the copyright holder 
of the original test (Üstün Zekalılar Enstitüsü, 2011).

TTCT-F assessment is based on three tasks: Picture construction, picture completion, and parallel lines. For each task, test takers are provided with stimuli including parallel or curvy lines. Using these stimuli, test takers are asked to produce as many figural drawings as possible in 10 minutes, as suggested by the TTCT-F manual (Torrance, 2008). Test takers are also asked to find titles for each drawing. The three tasks are included in the scoring procedure that yields five subscores, which are fluency, originality, abstractness of titles, elaboration, and resistance to premature closure (RPC).

\subsubsection{Wechsler Intelligence Scale for Children-Revised (WISC-R) Coding Subtest.}

The data on the processing speed of participants came from the Wechsler Intelligence Scale for Children - Revised (WISC-R) (Turkish version) score reports that were required from parents by the schools to assess the eligibility of the student for the gifted program. Despite the fact that the original WISC-R (English version) was developed more than 40 years ago (Wechsler, 1974) and that the only Turkish adaptation, standardization, and norming on Turkish children was done more than 20 years ago (Savaşır \& Şahin, 1995), WISC-R remains as almost the only intelligence test accepted for identification of the gifted both in public and private schools in Turkey. Please note that the current original (English) edition of WISC is WISC-V, which has improved technical qualities and norms.

The scaled scores of the participants for the Coding subtest of WISC-R were used as data for processing speed. In the Coding subtest, each of a number of geometric shapes or numbers is paired with a simple symbol, as presented to the examinee on top of a sheet. The examinee is asked to copy these symbols in or below each of the geometric shapes or numbers printed in random order many times on the sheet. The examinee's score is calculated based on the number of symbols correctly drawn within the 120-second time limit (Savaşır \& Şahin, 1995).

\subsection{Data Collection and Scoring}

Data collection was completed by one of the researchers, who were also the coordinator of the programs designed for the gifted in the participating schools. Therefore, the researcher had access to the records of the students participating in the programs. The researcher also had regular visits to the programs in these schools.

TTCT-F administration took place between March 2015 and June 2015. The test was group-administered by the researcher to the participating students during each school's pull-out gifted program, still in the school's own building. The researcher visited each classroom and administered the TTCT-F. Each of the three tasks was administered in 10 minutes, as suggested by the TTCT-F manual (Torrance, 2008). WISC-R (Turkish version) Coding subtest scores of participants were collected from student records.

The forms were scored by the researchers according to the criteria and guidelines provided in the TTCT-F manual (Torrance, 2008). Scoring generated five subscores, which were fluency, elaboration, originality, RPC, and abstractness of titles. Since the test has not been normed for any Turkish population, only raw subscores were calculated for each participant. For drawings in each of the three tasks of picture construction, picture completion, and parallel lines, possible raw subscores for fluency and originality vary in range from zero to no upper limit; for elaboration from zero to six; for RPC from zero to two; for abstractness of titles from zero to three. Possible values for scaled scores of the WISC-R Coding subtest, which were also used as the scores of processing speed, ranged from 1 to 19.

\section{Results}

There were no missing values in our dataset. Independent samples t-test was performed to compare group mean differences; Pearson product moment correlation coefficient was calculated to examine the correlations between variables. For all data analyses, SPSS 19.0 (SPSS Inc., 2010) was used.

Our first research question was whether there were differences between gifted girls and boys in processing speed and dimensions of creativity. Table 1 shows that females had statistically significantly higher scores in processing speed, elaboration, abstractness of titles, and RPC. There were no significant differences in fluency and originality. According to Cohen's (1988) broadly defined standards, Cohen's d value for processing speed (.39) reflects a small-to-medium effect size; while the other three statistically significant differences can be said to have medium-to-large effect sizes. 
Table 1. Results of t-tests and descriptive statistics for processing speed and creativity subscores

\begin{tabular}{|c|c|c|c|c|c|c|c|c|c|}
\hline & \multicolumn{6}{|c|}{ Group } & \multirow[b]{3}{*}{$\mathrm{t}$} & \multirow[b]{3}{*}{$\mathrm{df}$} & \multirow[b]{3}{*}{ Cohen's d } \\
\hline & \multicolumn{3}{|c|}{ Male } & \multicolumn{3}{|c|}{ Female } & & & \\
\hline & $\mathrm{M}$ & $\mathrm{SD}$ & $\mathrm{n}$ & M & $\mathrm{SD}$ & $\mathrm{n}$ & & & \\
\hline Processing speed & 13.20 & 3.03 & 75 & 14.12 & 1.80 & 58 & $2.18 *$ & 123.53 & .39 \\
\hline Fluency & 18.32 & 8.83 & 75 & 20.22 & 5.99 & 58 & 1.48 & 128.96 & .26 \\
\hline Originality & 11.32 & 5.64 & 75 & 10.47 & 4.40 & 58 & .98 & 130.99 & .17 \\
\hline Elaboration & 6.64 & 5.07 & 75 & 9.72 & 5.85 & 58 & $3.19 *$ & 113.07 & .60 \\
\hline Abstractness of titles & 4.72 & 4.2 & 75 & 8.29 & 5.89 & 58 & $3.91 *$ & 98.81 & .79 \\
\hline $\begin{array}{l}\text { Resistance to } \\
\text { premature closure }\end{array}$ & 11.36 & 3.54 & 75 & 14.34 & 4.46 & 58 & $4.18^{*}$ & 106.62 & .81 \\
\hline
\end{tabular}

Note. Equal group variances not assumed.

$* \mathrm{p}<.05$ (two-tailed).

Following up on the differences reported in the literature between males and females in terms of mental processing, our second research question asked whether the trend in the correlations between processing speed and creativity subscores was similar for gifted boys and girls. As can be seen in Table 2, this trend was totally different for males and females. While fluency and originality were the only two subscores correlated with processing speed for males, originality, elaboration, abstractness of titles, and RPC were the subscores that were correlated with processing speed for females. It is also interesting to see that the two correlations mentioned above for males were positive; while the above four correlations for females were negative.

Table 2. Correlations between processing speed and subscores of creativity

\begin{tabular}{|c|c|c|c|c|c|c|}
\hline & & Fluency & Originality & Elaboration & Abstractness of titles & Resistance to premature closure \\
\hline \multicolumn{7}{|c|}{ Males $(\mathrm{n}=75)$} \\
\hline Processing speed & $\mathrm{r}$ & $.421 *$ & $.374 *$ & -.112 & .084 & .163 \\
\hline \multicolumn{7}{|c|}{ Females $(\mathrm{n}=58)$} \\
\hline Processing speed & $\mathrm{r}$ & -.061 & $-.289 *$ & $-.254 *$ & $-.335^{*}$ & $-.661 *$ \\
\hline
\end{tabular}

$* \mathrm{p}<.05$ (two-tailed).

Inspired by the threshold theory we explained in the literature review, our third research question was about the strength of relationship between processing speed and each of the dimensions of creativity for groups of low and high giftedness. We labeled students with an IQ score of 130 or below as the group of low, and above 130 as the group of high giftedness in this study. There were two reasons why we used the cutoff value of 130. First, IQ scores used in this study are based on the Turkish norms developed in 1995 (Savaşır \& Şahin, 1995). As supported by the finding, which is also known as the Flynn effect, that there have been significant gains in IQ scores in many countries over the years (Flynn, 1987), there has been an inflation in identification of the gifted in Istanbul. Consequently, many schools with programs for the gifted currently use cutoff scores much higher than 115 to admit students to their programs for the gifted. The second, more practical reason was that using the cutoff value of 130 gave us sufficient numbers of students for the two groups, allowing a healthy comparison. In the literature on the threshold theory, there is no consensus on what the threshold score value is.

In view of the differences between males and females in terms of processing speed and dimensions of creativity, we thought we should also consider gender while examining these variables for groups of low and high giftedness. Table 3 gives descriptive statistics of processing speed and creativity subscores for level of giftedness by gender, and also provides results of t-tests between male and female students for the groups of low and high giftedness. There are statistically significant differences between males and females in favor of females in processing speed, elaboration, abstractness of titles, and RPC in the group of low giftedness. Yet, there are two statistically significant differences between males and females in the group of high giftedness, still in favor of females, which are in elaboration and abstractness of titles. According to Cohen's (1988) standards, the Cohen's d values reflect at least a medium effect size for all the statistically significant mean differences reported for the two groups in Table 3. 
Table 3. Results of t-tests and descriptive statistics for processing speed and creativity subscores (Level of giftedness by gender)

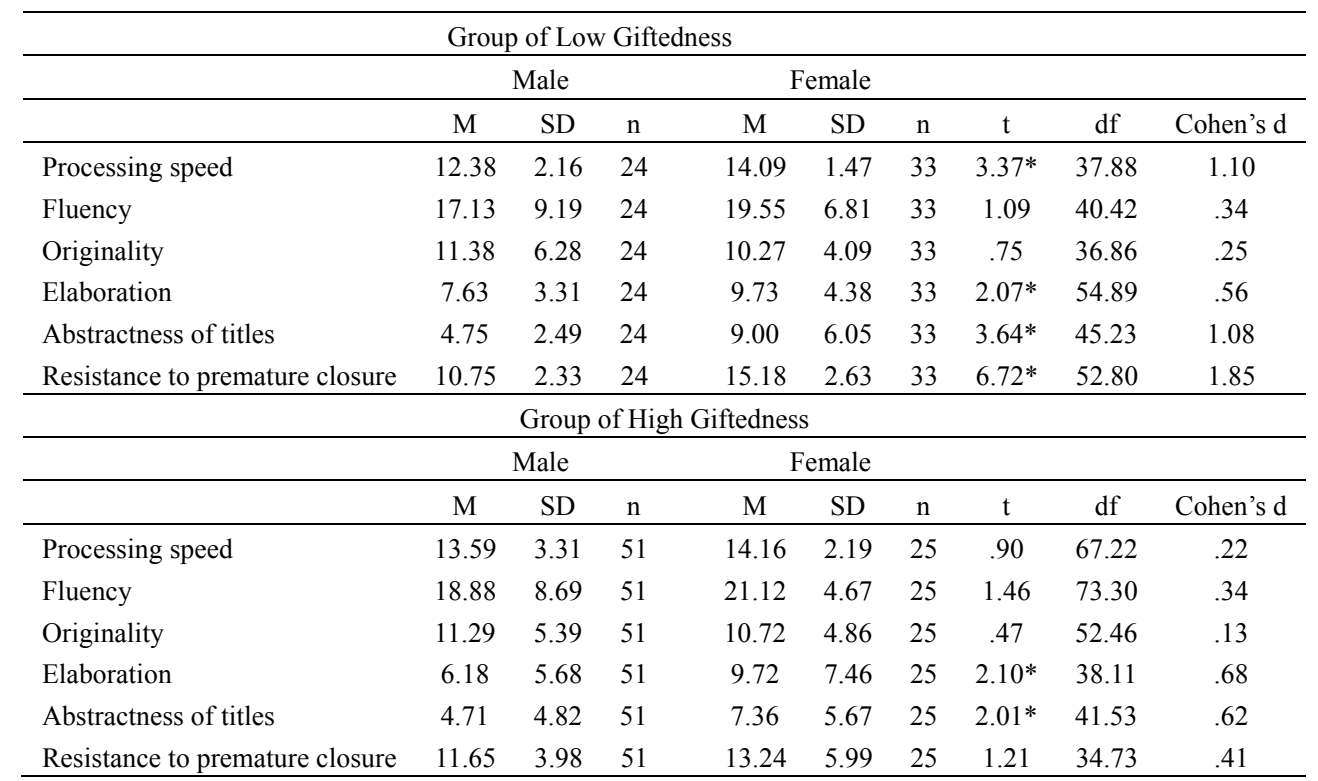

Note. Equal group variances not assumed.

$* \mathrm{p}<.05$ (two-tailed).

Correlations for level of giftedness by gender given in Table 4 exhibit differences between males and females within each group of giftedness. They also reveal same-gender differences between the two groups of giftedness. The differences are not only in the magnitudes of correlations but also in their directions. For example, it is interesting to see that none of the correlations between processing speed and each of the five creativity subscores were statistically significant for males in the group of low giftedness; while for females in the same group of low giftedness, there were three statistically significant correlations (all negative), which were between processing speed and each of the three subscores of elaboration, abstractness of titles, and RPC. Furthermore, for males in the group of high giftedness, processing speed had high positive correlations with fluency and originality; while the two statistically significant correlations for females in the group of high giftedness were between processing speed and each of originality and RPC. Yet these two high correlations for females were negative.

Table 4. Correlations between processing speed and subscores of creativity (Level of giftedness by gender)

\begin{tabular}{|c|c|c|c|c|c|c|}
\hline \multicolumn{7}{|c|}{ Group of Low Giftedness } \\
\hline & & Fluency & Originality & Elaboration & Abstractness of titles & Resistance to premature closure \\
\hline \multicolumn{7}{|c|}{ Males $(n=24)$} \\
\hline Processing speed & $\mathrm{r}$ & .083 & -.357 & -.289 & .188 & .201 \\
\hline \multicolumn{7}{|c|}{ Females $(n=33)$} \\
\hline Processing speed & $\mathrm{r}$ & .117 & .105 & $-.420 *$ & $-.444 *$ & $-.491 *$ \\
\hline \multicolumn{7}{|c|}{ Group of High Giftedness } \\
\hline & & Fluency & Originality & Elaboration & Abstractness of titles & Resistance to premature closure \\
\hline \multicolumn{7}{|c|}{ Males $(\mathrm{n}=51)$} \\
\hline Processing speed & $\mathrm{r}$ & $.529 *$ & $.657^{*}$ & -.054 & .071 & .135 \\
\hline \multicolumn{7}{|c|}{ Females $(\mathrm{n}=25)$} \\
\hline Processing speed & $\mathrm{r}$ & -.311 & $-.590 *$ & -.168 & -.249 & $-.762 *$ \\
\hline
\end{tabular}

$* \mathrm{p}<.05$ (two-tailed).

\section{Discussion}

The purpose of this study was to explore the relationship between processing speed and dimensions of creativity. To our knowledge, no prior researchers have investigated this relationship empirically. The present study examines 
this relationship also relating it to gender and level of giftedness, which adds to its uniqueness.

Our first research question was whether there were differences between gifted girls and boys in processing speed and dimensions of creativity. In line with prior studies (Camarata \& Woodcock, 2006; Feingold, 1992; Longman et al., 2007; Majeres, 2007; Reynolds et al., 1987; Sheppard \& Vernon, 2008; Silverman, 2006; Wechsler, 1997), our findings indicated that gifted girls were significantly better than gifted boys in processing speed which was measured through WISC-R Coding subtest. Although the findings of this study together with those of previous research might confirm female superiority in processing speed, we have no theoretical explanations for these differences. Rushton and Jensen (2005) suggest that educational and cultural factors affect processing speed tasks less than they do other psychometric tasks; therefore, it is reasonable to think that cognitive factors lead to gender differences in processing speed tasks. However, the literature regarding processing speed does not seem to have uncovered any cognitive factors causing gender differences in processing speed (Roivainen, 2011). Putting aside the impact of factors contributing to gender differences in processing speed, our findings suggest that gender differences in basic abilities, such as processing speed, might lead to gender differences in other basic or higher order skills, too. For example, considering detrimental effects of processing speed on reading fluency and comprehension (Jacobson et al., 2011), it is reasonable to expect gender differences in reading ability performances. We recommend future researchers to consider such complicated interrelationships among skills when investigating differences in boys' and girls' performances.

Our findings related to gender differences in dimensions of creativity showed that gifted girls had significantly higher scores than gifted boys on three dimensions of creativity, namely, elaboration, abstractness of titles, and RPC. However, there were no significant differences in fluency and originality scores. In this sense, our findings resemble those of Bart et al. (2015), who found statistically significant differences between eighth grade males and females in all dimensions of creativity except fluency. All differences were in favor of females. For $11^{\text {th }}$ grade students, the statistically significant differences were still in favor of females in elaboration, abstractness of titles, and RPC; and there were no differences in originality and fluency.

Bart et al. (2015) present Kirton's (as cited in Bart et al., 2015) Adaptation-Innovation theory as an explanation of their findings, which suggests that individuals' approaches to problem solving are either adaptive or innovative. An adaptor looks for the best solution; while an innovator seeks a novel solution. Bart et al. (2015) also cite results of a factor analytic study by Kim (2006) that fluency and originality loaded onto the innovative factor; elaboration and abstractness of titles loaded onto the adaptive factor; while RPC loaded onto both factors. This explanation leads us to think that females show higher adaptive skills than males, while males and females are equally innovative. Furthermore, as Bart et al. (2015) stated, these findings might suggest that "females elaborate more with their ideas, present more detail in their responses, manifest significantly higher synthesizing and organization skills, and display more intellectual curiosity and open-mindedness compared to the males" (p. 22). As a result, our findings also provide some level of support for the Adaptation-Innovation theory. Among our findings, those that are not entirely in line with this theory can be attributed to many other variables that have a relationship with creativity.

We also suggest that females' better performance in 'abstractness of titles' dimension of creativity might be associated with their better language performance. Prior studies consistently indicated female superiority in language performance, such as earlier and quicker vocabulary development (Huttenlocher, Haight, Bryk, Seltzer, \& Lyons, 1991), greater syntactic complexity (Bornstein, Chun-Shin, \& Haynes, 2004), and early talking (Murray, Johnson, \& Peters, 1990). According to the scoring manual of TTCT, to be able to score higher in 'abstractness of titles' dimension of creativity, a test-taker has to perform better in labeling figures, which requires abstract and meaningful use of language. From this point of view, linking a better performance in 'abstractness of titles' dimension of creativity with better performance in language would be reasonable.

In regard to our second research question, which asked whether the trend in the correlations between processing speed and creativity subscores was similar for gifted boys and girls, the findings indicated that fluency and originality were the only two subscores positively correlated with processing speed for males. On the other hand, originality, elaboration, abstractness of titles, and RPC were negatively correlated with processing speed for females. As indicated before, females are found to be better at elaboration, abstractness of titles, and RPC. Due to their time-consuming nature, high performance in these dimensions might require spending more time in related tasks, causing a reduction in processing speed, and eventually leading to significant negative correlations between processing speed and these dimensions.

Our third research question was about a possible differential trend in correlations between processing speed and dimensions of creativity for the group of low giftedness versus that of high giftedness. No dimension of 
creativity has a significant correlation with processing speed for boys of low giftedness. On the other hand, there were significant negative correlations between processing speed and each of elaboration, abstractness of titles, and RPC for girls of low giftedness; while the other two dimensions had no correlation with processing speed (see Table 4). These findings for girls of low giftedness are identical with the ones for the whole group of girls in this study, and we have already elaborated on these negative correlations for girls in the previous paragraph.

Another finding about the third research question is the high positive correlations of fluency and originality with processing speed reported in Table 4 together with a correlation of .76 between fluency and originality for highly gifted boys. So far, researchers have already established a positive correlation between fluency and originality (e.g., Simonton, 1990; Torrance \& Safter, 1999). In practical terms, such a correlation means that if someone produces a large number of ideas, $\mathrm{s} / \mathrm{he}$ is more likely to be original in his/her ideas. In other words, there is a direct relationship between the quality and the quantity of ideas or alternatives produced. This relationship has also been expressed in Osborn's (1963) 'quantity breed quality' hypothesis: "It is almost axiomatic that quantity breeds quality in ideation. Logic and mathematics are on the side of the truth that the more ideas we produce, the more likely we are to think up some that are good" (p. 131). Our finding turns this relationship into a trio of fluency, originality, and speed, at least for highly gifted boys, suggesting that if someone produces a large number of ideas, this person is more likely to be not only original but also faster in producing ideas or alternatives. In this study, these high positive correlations are distinctly valid for highly gifted boys, but not for boys of low giftedness or girls of high giftedness. Such a finding might imply a threshold theory for the triangular relationship among these variables, suggesting that highly gifted boys are a unique group in the utilization of their cognitive abilities.

The disagreement between our findings and those of some of the previous researchers suggests that the investigation and discussion of processing speed and dimensions of creativity should be more task-specific. One can come across several operational definitions of processing speed, such as the speed of paper-and-pencil coding, reaction time, finger tapping, and rapid naming of objects (Roivainen, 2011). One might also encounter various definitions and / or domains of creativity. An obvious example is creativity in figural and verbal domains. It follows that findings on visual versus kinesthetic processing speed, or on fluency (a dimension of creativity) in figural versus verbal material might be different. Such variation in definitions is also highly likely to result in differential findings around the relationship between processing speed and creativity due to the interaction between the two. This fact opens up a wide area of research, hosting a multitude of variables, since these variables might also be keys to understanding differences between/among groups of age, gender, culture, etc.

The findings of the study also have an implication about the identification of the gifted. The finding that processing speed is negatively correlated with elaboration and RPC for girls might cause a disadvantage for girls in identification. Girls have significantly higher scores in elaboration and RPC. Girls' elaborating more on the tasks they are presented with might bring about a disadvantage for them in tasks where elaboration is not rewarded, yet faster completion of the task is rewarded in the form of earned points. While not earning points for elaboration, they might be losing points for longer times to complete the tasks. This might cause poorer results for girls, especially in gifted assessments, where tasks presented are open-ended and available for elaboration, and time to complete tasks significantly affects the assessment results. As a remedy to this problem, in addition to assessments that use processing speed as a measure but do not use dimensions of creativity (such as elaboration and RPC) as measures, performance levels in dimensions of creativity can be utilized as additional criteria in the identification of the gifted. In this way, girls' significantly higher scores in elaboration and RPC might compensate for this disadvantage.

Perhaps, the biggest limitation of this study was that the scores from the Coding subtest of WISC-R were the only measure of processing speed. The other subtest of WISC-R (Symbol Search), which is used together with Coding in the calculation of the Processing Speed Index, could not be used, since it is an optional subtest. Therefore, Symbol Search scores were not available for all participants. We could not find other measures of processing speed that could be obtained easily and reliably from our participants.

A second issue is about the formation of groups of low and high giftedness. We have used WISC-R (Turkish version) scores to form these groups. However, please note that the original WISC-R (in English) was developed in 1974 (Wechsler, 1974), and the Turkish version was adapted and normed in 1995 (Savaşır \& Şahin, 1995). Therefore, the cutoff value of an IQ score of 130 we have used to split our sample into two groups of giftedness reflects norms that are more than 20 years old. In this sense, the IQ score of 130 in this study should, in no way, be compared to scores based on current versions and / or norms of WISC developed for any country. This fact, on the other hand, does not hurt the comparability of students' IQ scores in this study, since all students took the same version of WISC, and their scores were calculated based on the same norms. Use of WISC-R scores and 
norms was inevitable, since it still is almost the only IQ test used in Turkey.

A third topic is the specificity of the sample. As the authors, we accept and acknowledge that the study sample is limited to a specific age group in a particular context. Therefore, all the findings of this study should be evaluated in light of this specificity.

Regarding a fourth matter, the Turkish version of TTCT-F has not been normed for any Turkish population. This makes it impossible to compare the study sample with their peers in Turkey in terms of their standing in creativity.

On a final note, no definite statements about causal relationships between variables can be made based on the findings of this non-experimental study. In this sense, tentative conclusions or interpretations made in this article need to be corroborated by studies of experimental nature or under conditions with some level of control. We still think that, around a topic little explored like the present one, suggesting brand new hypotheses and providing tentative explanations about the nature of relationships between variables contribute to the field significantly through offering valuable insight to future researchers in their research design and variables to consider.

\section{References}

Abra, J. (1991). Gender differences in creative achievement: A survey of explanations. Genetic, Social \& General Psychology Monographs, 117(3), 235-285.

Abraham, A. (2016). Gender and creativity: An overview of psychological and neuroscientific literature. Brain Imaging and Behavior, 10(2), 609-618. https://doi.org/10.1007/s11682-015-9410-8

Anwar, M. N., Shamim-ur-Rasool, S., \& Haq, R. (2012). A comparison of creative thinking abilities of high and low achievers secondary school students. International Interdisciplinary Journal of Education, 1(1), 1-6.

Awamleh, H., Al Farah, Y., \& El-Zraigat, I. (2012). The level of creative abilities dimensions according to Torrance formal test (B) and their relationship with some variables (Sex, Age GPA). International Education Studies, 5(6), 138-148. https://doi.org/10.5539/ies.v5n6p138

Ayyıldız-Potur, A., \& Barkul, Ö. (2009). Gender and creative thinking in education: A theoretical and experimental overview. ITU Journal of the Faculty of Architecture, 6(2), 44-57.

Baer, J., \& Kaufman, J. C. (2008). Gender differences in creativity. The Journal of Creative Behavior, 42(2), 75-105. https://doi.org/10.1002/j.2162-6057.2008.tb01289.x

Bart, W. M., Hokanson, B., Sahin, I., \& Abdelsamea, M. A. (2015). An investigation of the gender differences in creative thinking abilities among 8th and 11th grade students. Thinking Skills and Creativity, 17, 17-24. https://doi.org/10.1016/j.tsc.2015.03.003

Batey, M., \& Furnham, A. (2006). Creativity, intelligence, and personality: A critical review of the scattered literature. Genetic, Social, and General Psychology Monographs, 132, 355-429. https://doi.org/10.3200/MONO.132.4.355-430

Bornstein, M. H., Chun-Shin, H., \& Haynes, O. M. (2004). Specific and general language performance across early childhood: Stability and gender considerations. First Language, 24(3), 267-304. https://doi.org/10.1177/0142723704045681

Brand, C. (1981). General intelligence and mental speed: Their relationship and development. In P. Friedman, P. Das, \& N. O'Connor (Eds.), Intelligence and learning (pp. 589-593). New York: Plenum Press. https://doi.org/10.1007/978-1-4684-1083-9_56

Camarata, S., \& Woodcock, R. (2006). Sex differences in processing speed: Developmental effects in males and females. Intelligence, 34, 231-252. https://doi.org/10.1016/j.intell.2005.12.001

Carroll, J. B. (1993). Human cognitive abilities: A survey of factor analytic studies. Australia: Press Syndicate of the University of Cambridge. https://doi.org/10.1017/CBO9780511571312

Charyton, C., \& Snelbecker, G. E. (2007). General, artistic and scientific creativity attributes of engineering and music students. Creativity Research Journal, 19, 213-225. https://doi.org/10.1080/10400410701397271

Cohen, J. (1988). Statistical power analysis for the behavioral sciences (2nd ed.). Hillsdale, NJ: Lawrence Erlbaum Associates.

Cramond, B. (1999). Going beyond the scores of the Torrance Tests of Creative Thinking. In A. S. Fishkin, B. Cramond, \& P. Olszewski-Kubilius (Eds.), Investigating creativity in youth (pp. 307-327). Creskill, NJ: 
Hampton Press.

Davidson, J. E., \& Sternberg. R. J. (1984). The role of insight in intellectual giftedness. Gifted Child Quarterly, 28(2), 58-64. https://doi.org/10.1177/001698628402800203

Deary, I. (2000). Simple information processing and intelligence. In R. Sternberg (Ed.), Handbook of intelligence (pp. 267-284). New York: Cambridge. https://doi.org/10.1017/CBO9780511807947.014

Deary, I. J. (1995). Auditory inspection time and intelligence: What is the direction of causation? Developmental Psychology, 31, 237-250. https://doi.org/10.1037/0012-1649.31.2.237

DeMoss, K., Milich, R., \& DeMers, S. (1993). Gender, creativity, depression, and attributional style in adolescents with high academic ability. Journal of Abnormal Child Psychology, 21(4), 455-467. https://doi.org/10.1007/BF01261604

Detterman, D. K. (1987). Theoretical notions of intelligence and mental retardation. American Journal of Mental Deficiency, 92(1), 2-11.

Feingold, A. (1992). Sex differences in variability in intellectual abilities: A new look at an old controversy. Review of Educational Research, 62, 61-84. https://doi.org/10.3102/00346543062001061

Feldman, D. H. (1982). Developmental approaches to giftedness and creativity (Vol. 1). San Francisco: Jossey-Bass Inc. Pub.

Flaherty, M. A. (1992). The effects of holistic creativity programs on the self-concept and creativity of third grades. Journal of Creative Behaviour, 26(3), 165-171. https://doi.org/10.1002/j.2162-6057.1992.tb01173.x

Fleith, D., Bruno-Faria, M., \& Alencar, E. M. (2014). Theory and practice of creativity measurement. Waco, TX: Prufrock Press.

Flynn, J. R. (1987). Massive IQ gains in 14 nations: What IQ tests really measure. Psychological Bulletin, 101, 171-191. https://doi.org/10.1037/0033-2909.101.2.171

Galton, F. (1883). Inquiries into human faculty and its development. London: Macmillan. https://doi.org/10.1037/14178-000

Guilford, J. P. (1950). Creativity. American Psychologist, 5, 444-454. https://doi.org/10.1037/h0063487

Guilford, J. P. (1967). The nature of human intelligence. New York: McGraw-Hill.

He, W., Wong, W., Li, Y., \& Xu, H. (2013). A study of the greater male variability hypothesis in creative thinking in Mainland China: Male superiority exists. Personality and Individual Differences, 55, 882-886. https://doi.org/10.1016/j.paid.2013.07.017

Hong, E., Peng, Y., O’Neil, H. F., \& Wu, J. (2013). Domain-general and domain-specific creative-thinking tests: Effects of gender and item content on test performance. The Journal of Creative Behavior, 47(2), 89-105. https://doi.org/10.1002/jocb.26

Huttenlocher, J., Haight, W., Bryk, A., Seltzer, M., \& Lyons, T. (1991). Early vocabulary growth: Relation to language input and gender. Developmental Psychology, 27(2), 236-248. https://doi.org/10.1037/0012-1649.27.2.236

Jacobson, L. A., Ryan, M., Martin, R. B., Ewen, J., Mostosfky, S. H., Denckla, M. B., \& Mahone, E. M. (2011). Verbal working memory influences processing speed and reading fluency in ADHD. Child Neuropsychology, 17(3), 209-224. https://doi.org/10.1080/09297049.2010.532204

Jauk, E., Benedek, M., Dunst, B., \& Neubauer, A. C. (2013). The relationship between intelligence and creativity: New support for the threshold hypothesis by means of empirical breakpoint detection. Intelligence, 41(4), 212-221. https://doi.org/10.1016/j.intell.2013.03.003

Jensen, A. R. (1982). Reaction time and psychometric g. In J. Eysenck (Ed.), A model for intelligence (pp. 93-132). New York: Springer. https://doi.org/10.1007/978-3-642-68664-1_4

Kaufman, J. C. (2006). Self-reported differences in creativity by ethnicity and gender. Applied Cognitive Psychology, 20(1), 1065-1082. https://doi.org/10.1002/acp.1255

Kaufman, J. C. (2009). Creativity 101. New York: Springer.

Kim, K. H. (2005). Can only intelligent people be creative? A meta-analysis. Journal of Secondary Gifted Education, 16(2/3), 57-66. https://doi.org/10.4219/jsge-2005-473

Kim, K. H. (2006). Is creativity unidimensional or multidimensional? Analyses of the Torrance Tests of Creative 
Thinking. Creativity Research Journal, 18(3), 251-259. https://doi.org/10.1207/s15326934crj1803_2

Kim, K. H., Cramond, B., \& VanTassel-Baska. J. (2010). The relationship between creativity and intelligence. In J. C. Kaufman, \& R. J. Sternberg (Eds.), The Cambridge handbook of creativity (pp. 395-412). New York: Cambridge University Press. https://doi.org/10.1017/CBO9780511763205.025

Kogan, N. (1974). Creativity and sex differences. The Journal of Creative Behavior, 8(1), 1-14. https://doi.org/10.1002/j.2162-6057.1974.tb01103.x

Kousoulas, F., \& Mega, G. (2009). Students' divergent thinking and teachers' ratings of creativity: Does gender play a role? The Journal of Creative Behavior, 43(3), 209-222. https://doi.org/10.1002/j.2162-6057.2009.tb01315.x

Longman, R. S., Saklofske, D. H., \& Fung, T. S. (2007). WAIS-III percentile scores by education and sex for U.S. and Canadian populations. Assessment, 14, 426-432. https://doi.org/10.1177/1073191107304114

Majeres, R. L. (2007). Sex differences in phonological coding: Alphabet transformation speed. Intelligence, 35, 335-346. https://doi.org/10.1016/j.intell.2006.08.005

Mumford, M. D. (2003). Where have we been, where are we going? Taking stock in creativity research. Creativity Research Journal, 15, 107-120. https://doi.org/10.1080/10400419.2003.9651403

Murray, A. D., Johnson, J., \& Peters, J. (1990). Fine tuning of utterance length to preverbal infants: Effects on later language development. Journal of Child Language, 17, 511-525. https://doi.org/10.1017/S0305000900010862

Neubauer, A. C. (1997). The mental speed approach to the assessment of inteligence. In J. Kingma, \& W. Tomic (Eds.), Advances in cognition and education: Reflections on the concept of intelligence (pp. 149-173). Greenwich, CT: JAI.

Osborn, A. F. (1963). Applied imagination (3rd ed.). New York: Charles Scribner's Sons.

Paz-Baruch, N., Leikin, M., Aharon-Peretz, J., \& Leikin, R. (2014) Speed of information processing in generally gifted and excelling-in-mathematics adolescents, High Ability Studies, 25(2), 143-167. https://doi.org/10.1080/13598139.2014.971102

Plucker, J. A. (1999). Is the proof in the pudding? Reanalyses of Torrance's (1958 to present) longitudinal data. Creativity Research Journal, 12, 103-114. https://doi.org/10.1207/s15326934crj1202_3

Preckel, F., Holling, H., \& Wiese, M. (2006). Relationship of intelligence and creativity in gifted and non-gifted students: An investigation of threshold theory. Personality and Individual Differences, 40, 159-170. https://doi.org/10.1016/j.paid.2005.06.022

Renzulli, J. S. (1978). What makes giftedness? Reexamining a definition. Phi Delta Kappan, 60(3), 180.

Renzulli, J. S., \& Reis. S. M. (1997). The schoolwide enrichment model: A how-to guide for educational excellence (2nd ed.). Mansfield Center, CT: Creative Learning Press.

Reynolds, C. R., Chastain, R. L., Kaufman, A. S., \& MacLean, J. E. (1987). Demographic characteristics and IQ among adults: Analysis of the WAIS-R standardization sample as a function of the stratification variables. Journal of School Psychology, 25, 323-342. https://doi.org/10.1016/0022-4405(87)90035-5

Rindermann, H., \& Neubauer, A. C. (2004). Processing speed, intelligence, creativity, and school performance: Testing of causal hypotheses using structural equation models. Intelligence, 32, 573-589. https://doi.org/10.1016/j.intell.2004.06.005

Roivainen, E. (2011). Gender differences in processing speed: A review of recent research. Learning and Individual Differences, 21(2), 145-149. https://doi.org/10.1016/j.lindif.2010.11.021

Roth, E. (1964). Die Geschwindigkeit der Verarbeitung von Information und ihr Zusammenhang mit Intelligenz. Zeitschrift für Experimentelle und Angewandte Psychologie, 11, 616-622.

Runco, M. A. (1986). Divergent thinking and creative performance in gifted and nongifted children. Educational and Psychological Measurement, 46, 375-384. https://doi.org/10.1177/001316448604600211

Runco, M. A. (2007). Creativity. Burlington, MA: Elsevier.

Runco, M. A. (2008). Commentary: Divergent thinking is not synonymous with creativity. Psychology of Aesthetics, Creativity, and the Arts, 2, 93-96. https://doi.org/10.1037/1931-3896.2.2.93

Runco, M. A., \& Albert, R. S. (1986). The threshold hypothesis regarding creativity and intelligence: An 
empirical test with gifted and nongifted children. Creative Child and Adult Quarterly, 11, 212-218.

Runco, M. A., \& Jaeger. G. J. (2012). The standard definition of creativity. Creativity Research Journal, 24(1), 92-96. https://doi.org/10.1080/10400419.2012.650092

Rushton, J. P., \& Jensen, A. R. (2005). Thirty years of research on race differences in cognitive ability. Psychology, Public Policy, and Law, 11, 235-294. https://doi.org/10.1037/1076-8971.11.2.235

Savaşır, I., \& Şahin, N. (1995). Wechsler Çocuklar İçin Zekâa Ölçeği (WISC - R) el kitabı. Ankara: Türk Psikologlar Derneği Yayınları.

Shanahan, M. A., Pennington, B. F., Yerys, B. E., Scott, A., Boada, R., Willcutt, E. G., \& DeFries, J. C. (2006). Processing speed deficits in attention deficit/hyperactivity disorder and reading disability. Journal of Abnormal Child Psychology, 34(5), 585-602. https://doi.org/10.1007/s10802-006-9037-8

Sheppard, L. D., \& Vernon, P. A. (2008). Intelligence and speed of information processing: A review of 50 years of research. Personality and Individual Differences, 44, 535-551. https://doi.org/10.1016/j.paid.2007.09.015

Shore, B. M., \& Lazar, L. (1996). IQ-related differences in time allocation during problem solving. Psychological Reports, 78(3), 848-850. https://doi.org/10.2466/pr0.1996.78.3.848

Silverman, I. W. (2006). Sex differences in simple visual reaction time: A historical meta-analysis. Sex Roles, 54, 57-68. https://doi.org/10.1007/s11199-006-8869-6

Silvia, P. J., Winterstein, B. P., Willse, J. T., Barona, C. M., Cram, J. T., Hess, K. I., ... Richard, C. A. (2008). Assessing creativity with divergent thinking tasks: Exploring the reliability and validity of new subjective scoring methods. Psychology of Aesthetics, Creativity, and the Arts, 2, 68-85. https://doi.org/10.1037/1931-3896.2.2.68

Simonton, D. K. (1990). Creativity and wisdom in aging. In J. E. Birren, \& K. W. Schaie (Eds.), Handbook of the psychology of aging (3rd ed., pp. 320-329). San Diego, CA: Academic. https://doi.org/10.1016/B978-0-12-101280-9.50025-5

Simonton, D. K. (1994). Greatness: Who makes history and why. New York: Guilford Press.

Sligh, A. C., Conners, F. A., \& Roskos-Ewoldsen, B. (2005). Relation of creativity to fluid and crystallized $\begin{array}{lllll}\text { intelligence. Journal of } & \text { Creative }\end{array}$ https://doi.org/10.1002/j.2162-6057.2005.tb01254.x

SPSS Inc. (2010). SPSS 19.0 [Computer software]. Chicago, IL: Author.

Steiner, H. H., \& Carr, M. (2003). Cognitive development in gifted children: Toward a more precise understanding of emerging differences in intelligence. Educational Psychology Review, 15(3), 215-246. https://doi.org/10.1023/A:1024636317011

Stephens, K. R., Karnes, F. A., \& Whorton, J. (2001). Gender differences in creativity among American Indian third and fourth grade students. Journal of American Indian Education, 40(1), 1-19.

Sternberg, R. J. (1985). Beyond IQ: A triarchic theory of human intelligence. CUP Archive.

Sternberg, R. J., \& O'Hara, L. (1999). Creativity and intelligence. In R. J. Sternberg (Ed.), Handbook of creativity (pp. 251-272). New York: Cambridge University Press.

Stoltzfus, G., Nibbelink, B. L., Vredenburg, D., \& Thyrum, E. (2011). Gender, gender role, and creativity. Social Behavior and Personality, 39(3), 425-432. https://doi.org/10.2224/sbp.2011.39.3.425

Tannenbaum, A. (1992). Early signs of giftedness: Research and commentary. Journal for the Education of the Gifted, 15, 104-133. https://doi.org/10.1177/016235329201500202

Tegano, D. W., \& Moran, J. D. (1989). Sex differences in the original thinking of preschool and elementary school children. Creativity Research Journal, 2(1-2), 102-110. https://doi.org/10.1080/10400418909534303

Torrance, E. P. (1962). Guiding creative talent. Englewood Cliffs, NJ: Prentice-Hall. https://doi.org/10.1037/13134-000

Torrance, E. P. (1966). Torrance Tests of Creative Thinking: Norms-technical manual. Princeton, NJ: Personnel Press.

Torrance, E. P. (1974). The Torrance Tests of Creative Thinking-Norms-Technical Manual Research Edition-Verbal Tests, Forms A and B-Figural Tests, Forms A and B. Princeton, NJ: Personnel Press.

Torrance, E. P. (2008). The Torrance Tests of Creative Thinking-Norms-Technical Manual-Figural 
(Streamlined) Forms A and B. Bensenville, IL: Scholastic Testing Service.

Torrance, E. P., \& Safter, H. T. (1999). Making the creative leap beyond. Buffalo, NY: Creative Education Foundation Press.

Üstün Zekalılar Enstitüsü. (2011). Turkish version of Torrance Test of Creative Thinking - Figural - Form A [Measurement instrument]. Istanbul, Turkey: Author.

Vincent, A. S., Decker, B. P., \& Mumford, M. D. (2002). Divergent thinking, intelligence, and expertise: A test of

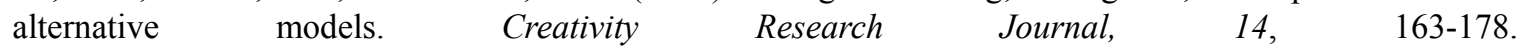
https://doi.org/10.1207/S15326934CRJ1402_4

Wallach, M. A., \& Kogan, N. (1965). Modes of thinking in young children. New York: Holt, Rinehart \& Winston.

Wechsler, D. (1974). Manual for the Wechsler Intelligence Scale for Children - Revised. New York: Psychological Corporation.

Wechsler, D. (1997). WAIS III administration and scoring manual. San Antonio: Psychological Corporation.

Woodcock, R. W., McGrew, K. S., \& Mather, N. (2001). Woodcock-Johnson III. Itasca, IL: Riverside.

\section{Copyrights}

Copyright for this article is retained by the author(s), with first publication rights granted to the journal.

This is an open-access article distributed under the terms and conditions of the Creative Commons Attribution license (http://creativecommons.org/licenses/by/4.0/). 